\title{
DIVERSITY IN BACTERIAL ISOLATES WITH CHANGING ANTIBIOTIC SENSITIVITY PATTERN IN CASES OF MENINGITIS FROM A TERTIARY CARE HOSPITAL, INDIA
}

\author{
Partha Sarathi Chakrabarty1, Moumita Adhikary²
}

${ }_{1}^{1}$ Assistant Professor, Department of Microbiology, College of Medicine and Sagore Dutta Hospital, Kolkata.

${ }^{2}$ Assistant Professor, Department of Microbiology, College of Medicine and Sagore Dutta Hospital, Kolkata.

ABSTRACT
BACKGROUND
Isolation of atypical bacteria and evaluation of their antibiotic resistance pattern in cases of meningitis is of critical importance.
Aims-
To isolate and identify the bacteria causing meningitis in patients admitted in a tertiary care hospital, India.
To evaluate the antimicrobial susceptibility pattern.

\section{MATERIALS AND METHODS}

Cerebrospinal fluid (CSF) and blood samples were collected from 83 clinically suspected patients suffering from meningitis. Direct smears were made from centrifuged CSF deposit and stained. Findings of Gram's stain, Ziehl-Neelsen stain and negative stain were reported. Cultures on 5\% sheep blood agar, MacConkey's agar and chocolate agar were done. The supernatant was used for latex agglutination test (LAT). Antibiotic susceptibility tests were performed for all isolates. Statistical analysis was done by Standard statistical software package - SPSS (version 18).

Study Design- Prospective observational study.

Settings- This work was carried out in patients who suffered from meningitis and were admitted in a tertiary care hospital, India. Tests were conducted at Department of Microbiology \& Central Laboratory in Katihar Medical College and Hospital, Bihar, India. Study Period- 2 years from 2009- 2011.

\section{RESULTS}

Out of 83 clinically suspected cases of meningitis, organisms were isolated from only 38 (45.8\%) patients. Out of these 38 cases, one patient was suffering from meningitis along with ruptured meningocoele, and had dual infection with Providencia spp. and Citrobacter spp. making a total of 39 bacterial isolates. Most common organism isolated was Escherichia coli 25.6\% (10/39), followed by Staphylococcus aureus 15.4\% (6/39), Streptococcus pneumoniae 10.2\% (4/39), Klebsiella species 10.2\% (4/39) and Pseudomonas aeruginosa 10.2\% (4/39). LAT detected bacterial antigens in 16.9\% (14/38) cases. Antibiotic susceptibility pattern showed maximum in vitro activity against Gram-negative bacilli by imipenem, amikacin and chloramphenicol. Imipenem and chloramphenicol had best in vitro activity against Gram-positive cocci. Majority of strains showed resistance to $3^{\text {rd }}$ generation cephalosporin.

\section{CONCLUSION}

The incidence of bacterial meningitis was more common with Gram-negative bacilli, Escherichia coli being the most common isolate. Established organisms of meningitis such as Haemophilus influenzae and Neisseria meningitidis were not isolated at all, despite all our efforts. All isolates were sensitive to imipenem, amikacin and chloramphenicol. All Gram-positive cocci were sensitive to imipenem with the increase in resistance to antibiotics like $3^{\text {rd }}$ generation cephalosporin. Thus, chloramphenicol which is not in much use these days and penetrates well into the cerebrospinal fluid may prove to be an alternate drug for treatment of meningitis.

\section{KEYWORDS}

CSF, Bacterial Meningitis, Antibiotic Susceptibility Pattern.

HOW TO CITE THIS ARTICLE: Chakrabarty PS, Adhikary M. Diversity in bacterial isolates with changing antibiotic sensitivity pattern in cases of meningitis from a tertiary care hospital, India. J. Evolution Med. Dent. Sci. 2017;6(93):6703-6707, DOI: $10.14260 /$ jemds/2017/1451

\section{BACKGROUND}

Bacterial meningitis is a leading cause of medical emengency. ${ }^{1}$ Inflammation of meninges, which may also spread to the subarachnoid space and CSF is Meningitis. ${ }^{2}$

'Financial or Other Competing Interest': None.

Submission 09-08-2017, Peer Review 21-11-2017,

Acceptance 27-11-2017, Published 11-12-2017.

Corresponding Author:

Dr. Moumita Adhikary,

9B, Ramtanu Bose Lane,

P. O. Beadon Street, P. S. Girish Park,

Kolkata-700006, West Bengal.

E-mail: drmoumitaadhikary@gmail.com

DOI: $10.14260 /$ jemds $/ 2017 / 1451$
Cases are presented with fever, headache, nausea and vomiting, lethargy, anorexia, irritability, photophobia, stiff neck with positive Kernig's sign. ${ }^{3}$ Common isolates responsible for bacterial meningitis are Streptococcus pneumoniae, Neisseria meningitidis, Haemophilus influenzae and enteric Gram-negative bacteria. ${ }^{4}$ Incidence of meningitis in USA between 1978 to 1981 was approximately 30/million population which dramatically reduced in 1995 due to vaccination with $\mathrm{Hi}^{ } \mathrm{b}$ and pneumococcal vaccines. 5 This was different in UK where an annual incidence rate per 1,00,000 children aged 0-16 years was 16.6 At Ahmedabad, in India, incidence varied from $12.12 \%$ to $56 \%$, while another study found only $1.5 \%$ of all admission in the hospital.7,8 A study from Maharashtra, found $36 \%$ of bacterial meningitis. ${ }^{9}$ 
Also, a 10-year retrospective study from South India showed $73.8 \%$ cases. ${ }^{10}$ Meningitis may be associated with significant mortality even after institution of therapy. ${ }^{3}$ Nearly one in every four adults with acute bacterial meningitis may die. Survivors may sustain neurological deficit. ${ }^{11}$ Early implementation of appropriate antimicrobial therapy requires prompt identification of the infecting pathogen. Therefore, in order to reduce the morbidity and mortality, it is imperious to have an early diagnosis and management of the patient. ${ }^{12}$ Culture which is gold standard along with latex agglutination test becomes an important diagnostic tool for interpretation of the aetiological agent. ${ }^{13,14}$ The irrational use of antibiotics only accelerates the emergence of antibiotic resistant strains apart from increasing the cost of therapy.

This present observational study is intended to reveal the diversity of bacterial isolates causing meningitis with their susceptibility pattern to different antibiotics in patients attending Katihar Medical College and Hospital, Bihar.

\section{MATERIALS AND METHODS}

This prospective observational study was conducted in the Department of Microbiology. All patients admitted with clinical suspicion of meningitis in Medicine and Paediatric Department and ICU were included. A detailed history including prior antibiotic intake, was recorded in a standard proforma. Written consent was obtained from all the patients for lumbar puncture including the history. Patients unfit for lumbar puncture were excluded from the study.

A total of 83 blood and CSF samples were collected. $2 \mathrm{~mL}$ of fluid was poured in a sterile vial under aseptic conditions. Macroscopic appearance was noted. Clear CSF with no turbidity was excluded. Only turbid samples were processed for microscopic examination by centrifugation at $2000 \mathrm{rpm}$ for $15 \mathrm{~min}$. at room temperature. Wet mount slides were made from deposits and examined under 40x magnification to allow quantification of WBC and then at $100 \mathrm{x}$ magnification under oil immersion. Organism and its morphology were reported. Gram's stain, culture, latex agglutination and antibiotic sensitivity tests were performed from CSF samples. Blood culture was also done along with CSF. For blood culture, 5-10 mL and 3-5 mL of blood were collected immediately from adults and children respectively, before institution of antibiotics.

CSF culture was done from deposit of centrifuged specimen by inoculating on glycerol broth, 5\% sheep blood agar, chocolate agar and MacConkey's agar. For Haemophilus influenzae, blood agar plates were streaked with Staphylococcus aureus Plzen strain. For Streptococcus pneumoniae, Bacitracin $0.04 \mu \mathrm{L}$ and Optochin discs were placed on blood agar plates streaked with CSF. Incubation was done at $37{ }^{\circ} \mathrm{C}$ in a candle jar with $5-10 \% \mathrm{CO}_{2}$ and observed daily for 72 hours. Both broth and blood culture bottles were incubated at $37^{\circ} \mathrm{C}$ and examined daily for 7 days. Turbidity was checked every day up to 7 days and irrespective of turbidity subculture was done. Any growth present on the plate or bottle was identified according to standard recommendations. ${ }^{2}$

CSF was also tested for bacterial antigens by latex agglutination using the BIO-RAD PASTOREX Meningitis Kit. The kit provided sera of Neisseria meningitidis A/B/C/Y/W135, Escherichia coli K1, H. influenzae type B,
Streptococcus pneumoniae, Streptococcus group B to detect antigens.

Antibiotic susceptibility test was done by Kirby - Bauer's disc diffusion method following CLSI guidelines. ${ }^{15}$

Statistical analysis was done by: Standard Statistical Software Package - SPSS (version 18).

Statistical analysis was determined by parametric \& nonparametric test. For comparison of means of two groups, student's test (sample size $<30$ ) or z test (sample size>30) was used. Analysis of Variance or ANOVA was done. Qualitative data analysis was done by Chi-square test.

\section{Null Hypothesis was Rejected when p value $<0.05$.}

1. Qualitative data - Doughnut chart.

2. Quantitative data - Bar graph.

\section{RESULTS}

The study population included 83 patients with clinically diagnosed meningitis. Maximum number of patients were seen among age group 18-65 years i.e. $30(36.1 \%)$ and least was found from birth to 6 months i.e. $11(13.6 \%)$ [Figure: 1]. Among all age groups, males were $50(60.2 \%)$ and females were 33 (39.8\%). (p value $<0.05$ ), [Figure: 2 ].

Smear positive cases were $27.7 \%$ only, while culture from CSF was positive in $38(45.7 \%)$ cases. In one patient with ruptured meningocoele associated with meningitis, two organisms were isolated from one CSF sample. They were Citrobacter spp. and Providencia spp. Therefore, total number of isolates was 39 out of 83. Escherichia coli was the most common pathogen isolated $10(25.6 \%)$ followed by Staphylococcus aureus 6 (15.4\%). Others like Pseudomonas aeruginosa, Klebsiella spp. and Streptococcus pneumoniae, were $4(10.3 \%)$ each. Only 1 patient grew Mycobacterium tuberculosis in culture with positive Ziehl-Neelsen staining and cobweb formation in CSF [Figure: 3].

Latex agglutination test detected bacterial antigens in 14 (16.8\%) out of 38 culture-positive cases. The common aetiological agents identified were Escherichia coli 10 (71.4\%) and Streptococcus pneumoniae 4 (28.5\%). In rest 24 (63.1\%) cases, no organism was detected. This is because of the unavailability of the antigens to some organisms.

All isolated Gram-negative bacilli were sensitive to amikacin, chloramphenicol and imipenem. Resistance was maximum with ceftriaxone $78.3 \%(18 / 23)$, cefotaxime $73.9 \%$ $(17 / 23)$, ceftazidime $69.6 \%(16 / 23)$ and ciprofloxacin $60.9 \%$ (14/23) [Table: 1]. Among Gram-negative isolates, all strains of Escherichia coli showed 90\% (9/10) resistance to ceftriaxone, ceftazidime and cefotaxime [Table: 2] Similarly, all strains of Gram-positive organisms were sensitive to amikacin and chloramphenicol- 100.0\% (15/15). Maximum resistance i.e. $60 \%(9 / 15)$ was seen with erythromycin [Table: 3]. Among Gram-positive isolates, all strains of Staphylococcus aureus were sensitive to amikacin and chloramphenicol and resistance was maximum with erythromycin $66.7 \%$ (4/6) followed by cotrimoxazole. Ceftriaxone, ciprofloxacin and gentamicin showed $33.3 \%$ (2/6) resistance. One strain of Staphylococcus aureus was found to be vancomycin resistant even on repeat testing [Table: 4]. 


\begin{tabular}{|c|c|c|}
\hline Antibiotics & $\begin{array}{l}\text { No. of Isolates } \\
\text { Sensitive (\%) }\end{array}$ & $\begin{array}{l}\text { No. of Isolates } \\
\text { Resistant (\%) }\end{array}$ \\
\hline Amikacin & $23(100.00)$ & $00(00.00)$ \\
\hline Ciprofloxacin & 09 (39.19) & $14(60.86)$ \\
\hline Cotrimoxazole & $15(65.21)$ & $08(34.78)$ \\
\hline Chloramphenicol & $23(100.00)$ & $00(00.00)$ \\
\hline Ceftriaxone & 05 (21.73) & $18(78.26)$ \\
\hline Ceftazidime & $07(30.43)$ & $16(69.56)$ \\
\hline Cefotaxime & $06(26.08)$ & $17(73.91)$ \\
\hline Imipenem & $23(100.00)$ & $00(00.00)$ \\
\hline Gentamicin & $20(86.95)$ & $03(13.04)$ \\
\hline \multicolumn{3}{|c|}{$\begin{array}{c}\text { Table 1. Antibiotic Susceptibility Pattern among Gram- } \\
\text { negative Organisms }\end{array}$} \\
\hline
\end{tabular}

$(n=23)$

\begin{tabular}{|c|c|c|}
\hline Antibiotics & $\begin{array}{c}\text { No. of Isolates } \\
\text { Sensitive (\%) }\end{array}$ & $\begin{array}{c}\text { No. of Isolates } \\
\text { Resistant (\%) }\end{array}$ \\
\hline Amikacin & $10(100.00)$ & $00(00.00)$ \\
\hline Ciprofloxacin & $03(30.00)$ & $07(70.00)$ \\
\hline Cotrimoxazole & $07(70.00)$ & $03(30.00)$ \\
\hline Chloramphenicol & $10(100.00)$ & $00(00.00)$ \\
\hline Ceftriaxone & $01(10.00)$ & $09(90.00)$ \\
\hline Ceftazidime & $01(10.00)$ & $09(90.00)$ \\
\hline Cefotaxime & $01(10.00)$ & $09(90.00)$ \\
\hline Imipenem & $10(100.00)$ & $00(00.00)$ \\
\hline Gentamicin & $09(90.00)$ & $01(10.00)$ \\
\hline \multicolumn{3}{|c|}{ Table 2. Antibiotic Susceptibility Pattern among } \\
\hline \multicolumn{3}{|c|}{ Escherichia coli } \\
\hline
\end{tabular}

$(n=10)$

\begin{tabular}{|c|c|c|}
\hline Antibiotics & $\begin{array}{l}\text { No. of Isolates } \\
\text { Sensitive (\%) }\end{array}$ & $\begin{array}{l}\text { No. of Isolates } \\
\text { Resistant (\%) }\end{array}$ \\
\hline Amikacin & $15(100.00)$ & $00(00.00)$ \\
\hline Cotrimoxazole & $08(53.33)$ & $07(46.66)$ \\
\hline Ceftriaxone & $11(73.33)$ & $04(26.66)$ \\
\hline Ciprofloxacin & $11(73.33)$ & $04(26.66)$ \\
\hline Gentamicin & $11(73.33)$ & $04(26.66)$ \\
\hline Erythromycin & $06(40.00)$ & $09(60.00)$ \\
\hline Chloramphenicol & $15(100.00)$ & $00(00.00)$ \\
\hline Vancomycin & $13(86.66)$ & $01(06.66)$ \\
\hline \multicolumn{3}{|c|}{$\begin{array}{l}\text { Table 3. Antibiotic Susceptibility Pattern among Gram- } \\
\text { positive Organisms }\end{array}$} \\
\hline
\end{tabular}

$(\mathrm{n}=15)$

\begin{tabular}{|c|c|c|}
\hline Antibiotics & $\begin{array}{c}\text { No. of Isolates } \\
\text { Sensitive }\end{array}$ & $\begin{array}{c}\text { No. of Isolates } \\
\text { Resistant }\end{array}$ \\
\hline Amikacin & $06(100.00)$ & $00(00.00)$ \\
\hline Cotrimoxazole & $04(66.67)$ & $02(33.33)$ \\
\hline Ceftriaxone & $04(66.67)$ & $02(33.33)$ \\
\hline Ciprofloxacin & $04(66.67)$ & $02(33.33)$ \\
\hline Gentamicin & $04(66.67)$ & $02(33.33)$ \\
\hline Erythromycin & $02(33.33)$ & $04(66.67)$ \\
\hline Chloramphenicol & $06(100.00)$ & $00(00.00)$ \\
\hline Vancomycin & $05(83.33)$ & $01(16.66)$ \\
\hline \multicolumn{2}{|c|}{ Table 4. Antibiotic Susceptibility Pattern among } \\
\hline \multicolumn{3}{|c|}{} \\
\hline
\end{tabular}

$(n=6)$

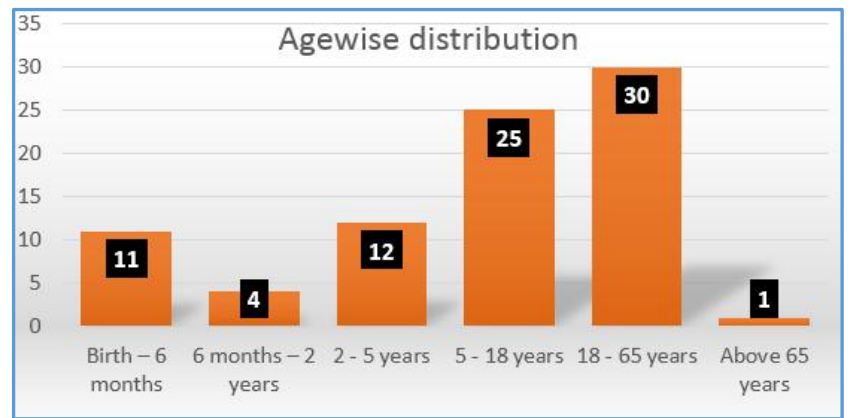

Figure. 1. Bar Graph showing Age Distribution among Cases of Meningitis

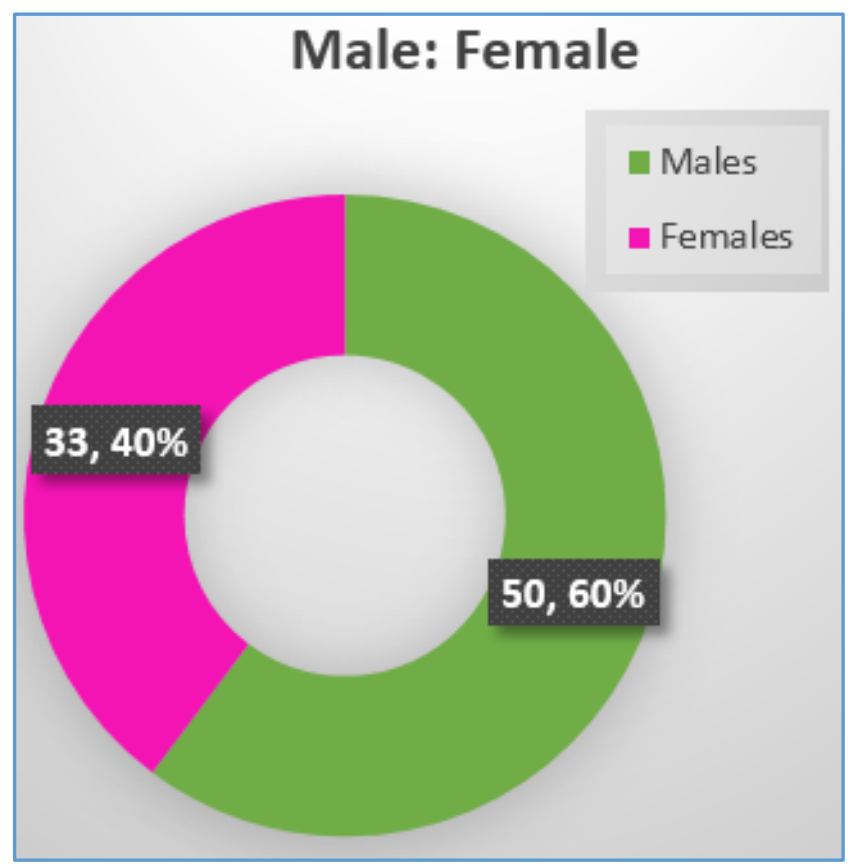

Figure 2. Shows Doughnut Chart with Male-Female Distribution

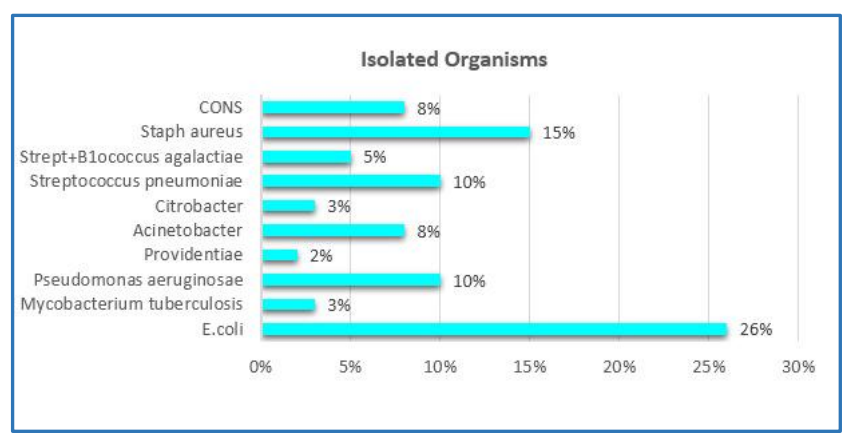

Figure 3. Clustered Bar Graph shows Organisms Isolated from CSF (\%)

\section{DISCUSSION}

Bacterial meningitis plays a major role in morbidity and mortality, despite the availability of effective antibiotics. Diagnosis of bacterial meningitis with the identification of the causal agent plays a crucial role in preventing unnecessary association or indiscriminate use of broad spectrum antibiotics.

In this prospective observational study, out of 83 clinically diagnosed meningitis patients, maximum number of patients belonged to $18-65$ years i.e. $30(36.1 \%)$ and least was found from birth to 6 months i.e. $11(13.6 \%)$ [Figure 1]. 
This was similar to Rao BN et al. ${ }^{16}$ With respect to sex, 50 (60.2\%) were male and $33(39.8 \%)$ were female among all age groups with an overall male to female ratio being 1.51:1 which were similar to other studies with ratios of $1.2: 1[5,17]$ and 1.69:1[18] ( $p$ value $<0.05$ ), [Figure: 2].

Smear-positive cases were seen in $27.7 \%$ only, while culture were positive in 38 (45.7\%) cases unlike previous reports.10,17 This proved culture as a gold standard technique. However, the total number of isolates were 39 out of 83 . This was because, two organisms were isolated from the CSF of a single patient with meningitis associated with ruptured meningocoele, isolates being Citrobacter spp. and Providencia spp. Out of 39 isolates, Escherichia coli was the most common pathogen isolated i.e. 10 (25.6\%) followed by Staphylococcus aureus i.e. 6 (15.4\%). Others like Pseudomonas aeruginosa, Klebsiella spp. and Streptococcus pneumoniae were 4 (10.3\%) each. Only 1 patient grew Mycobacterium tuberculosis in culture with positive Ziehl-Neelsen staining and cobweb formation in CSF [Figure: 3] These findings were different from Raja NS et al, probably because it included all age groups. ${ }^{17}$ Present study was quite similar to a study conducted in Nepal with respect to the isolated organisms, specially, the Gram-negative isolates. ${ }^{19}$ Blood cultures were positive in only $56.6 \%$ cases of bacterial meningitis which was similar to other findings with $58.4 \%$ positivity. ${ }^{17}$

Latex agglutination test detected bacterial antigens in 14 $(16.8 \%)$ out of 38 culture-positive cases. Where again, common aetiological agents was identified as Escherichia coli, $10(71.4 \%)$ and Streptococcus pneumoniae, 4 (28.5\%). In the remaining 24 (63.1\%) cases, no organisms could be detected. This was because of the unavailability of the antigens to some organisms, and the findings were similar to Surinder K et al. ${ }^{20}$ Organisms such as Neisseria meningitidis $\mathrm{B} / \mathrm{C} / \mathrm{Y} / \mathrm{W} / 35$ and Haemophilus influenzae type $\mathrm{b}$ were not found at all.

All isolated Gram-negative bacilli were sensitive to amikacin, chloramphenicol and imipenem. Resistance was maximum to ceftriaxone $78.3 \%(18 / 23)$, cefotaxime $73.9 \%$ (17/23), ceftazidime $69.6 \%(16 / 23)$ and ciprofloxacin $60.9 \%$ (14/23) [Table: 1]. Among Gram-negative isolates, all strains of Escherichia coli showed $90 \%$ (9/10) resistance to ceftriaxone, ceftazidime and cefotaxime [Table: 2]. Similarly, all strains of Gram-positive organisms were sensitive to amikacin and chloramphenicol. Maximum resistance i.e. $60 \%$ (9/15) was seen with erythromycin [Table: 3]. The above results were quite similar to a study by Tiwari KB et al. ${ }^{19}$

Among Gram-positive isolates, all strains of Staph. aureus were sensitive to amikacin and chloramphenicol and resistance was maximum with erythromycin $66.7 \%$ (4/6) like Tiwari KB et al, followed by cotrimoxazole. ${ }^{19}$ Ceftriaxone, ciprofloxacin and gentamicin showed $33.3 \%(2 / 6)$ of resistance. One strain of Staphylococcus aureus was found to be vancomycin resistant $16.7 \%(1 / 6)$ even on repeat testing [Table: 4], which was unlike Tiwari et al where $50.0 \%$ of their Staphylococcus aureus strains were resistant to amikacin and resistance to vancomycin was nil. ${ }^{19}$

\section{CONCLUSION}

Thus, to conclude, the present study shows a predominance of Gram-negative enteric bacilli as the causative agent causing bacterial meningitis, where Escherichia coli was the most common isolate. Organisms like Haemophilus influenzae and Neisseria meningitidis were not isolated in-spite of all our efforts. This could probably be due to widespread Hib vaccine for Haemophilus influenzae among children, even in rural and semi-urban areas. Moreover, Neisseria meningitidis is known for epidemic meningitis and isolation during inter-epidemic period is generally low. Also, these two organisms are very delicate; they die off easily and are very difficult to culture. Isolation of Gram-positive bacteria was comparatively lower in number. The organisms isolated were Staphylococcus aureus, Streptococcus pneumoniae, CONS and Streptococcus agalactiae.

All isolates were sensitive to amikacin and chloramphenicol. All Gram-positive cocci were sensitive to imipenem. Majority of strains showed resistance to $3^{\text {rd }}$ generation cephalosporin. One strain of Staphylococcus aureus was vancomycin resistant, even on repeat testing (further confirmation by MIC studies indicated). Thus, chloramphenicol which is not in much use these days and penetrates well into the cerebrospinal fluid may prove to be an alternate drug for treatment of meningitis.

\section{Limitations of the Study}

Further studies regarding occurrence of other pathogens causing bacterial meningitis like Haemophilus influenzae, Neisseria meningitidis, Listeria monocytogenes and fungi like Cryptococcus neoformans are indicated in the future preferably by PCR of the CSF especially in view of the fact that these organisms which are established causes of meningitis were not isolated in the present study.

\section{REFERENCES}

[1] Prober CG. Central nervous system infections. In: Berman RE, Kliegman RM, Jenson HB. eds. Nelson textbook of Paediatrics. 16 ${ }^{\text {th }}$ edn. Philadelphia: WB Saunders 2000:751-7.

[2] Forbes BA, Sahm DF, Weissfeld AS. Meningitis and other infections of the central nervous system. Bailey and Scott's diagnostic microbiology. $12^{\text {th }}$ edn. Missouri: Mosby Elsevier 2007;55:822-31.

[3] Roos KL, Tyler KL. Meningitis, encephalitis, brain abscess and empyema. In: Kasper DL, Braunwald E, Fauci AS, et al. eds. Harrison's principles of internal medicine. 17th edn. USA: McGraw-Hill Comp Inc., 2008;2:2621-41.

[4] Hart CA, Cuevas LE. Bacterial meningitis. In: Cook G, Zumla A. eds. Manson's tropical diseases. 21 $1^{\text {st }}$ edn. London: ELST with Saunders 2003;8(56):981-94.

[5] Schlech WF III, Ward JI, Band JD, et al. Bacterial meningitis in the United States, 1978 through 1981. The National Bacterial Meningitis Surveillance Study. JAMA 1985;253(12):1749-54.

[6] Fortnum HM, Davis AC. Epidemiology of bacterial meningitis. Arch Dis Childhood 1993;68(6):763-7.

[7] Panjarathinam R, Shah RK. Pyogenic meningitis in Ahmedabad. Indian J Paedtr 1993;60(5):669-73.

[8] Seetha KS, Murthy R, Shivananda PG. Incidence of meningitis in Manipal. Indian J Pub Health 1999;43(2):82-4.

[9] Tankhiwale SS, Jagtap PM, Khadse RK, et al. Bacteriological study of pyogenic meningitis with 
special reference to C-reactive protein. Indian J Med Microbiol 2001;19(3):159-60.

[10] Mani R, Pradhan S, Nagarathna S, et al. Bacteriological profile of community acquired acute bacterial meningitis: a ten year retrospective study in a tertiary neurocare centre in South India. Indian J Med Microbiol 2007;25(2):108-14.

[11] Jones ME, Dragchi DC, Karlowsky JA, et al. Prevalence of antimicrobial resistance in bacteria isolated from central nervous system specimen as reported by US hospital laboratories from 2000 to 2002. Ann Clin Microbiol Antimicrob 2004:3:3.

[12] Akpede GO, Abiodun PO, Ambe JP, et al. Presenting features of acute bacterial meningitis in young infants. Ann Trop Paediatr 1994;14(3):245-52.

[13] Dunbar SA, Eason RA, Musher DM, et al. Microscopic examination and broth culture of cerebrospinal fluid in diagnosis of meningitis. J Clin Microbiol 1998;36(6):1617-20.

[14] Deivanayagam N, Ashok TP, Nedunchelium K, et al. Bacterial meningitis: diagnosis by latex agglutination test and clinical features. Indian Pediatr 1993;30(4):495-500.
[15] CLSI. Performance standards for antimicrobial susceptibility testing: eighteenth informational supplement, M100-S18. 2008;28(1):1-179.

[16] Rao BN, Mahdi I, Shembesh NM, et al. Etiology and occurrence of acute bacterial meningitis in children in Benghazi, Libyan Arab Jamahiriya. Eastern Mediterranean Health J 1998;4(1):50-7.

[17] Raja NS, Parasakthi N, Puthucheary SD, et al. Invasive meningococcal disease in the university of Malaya Medical Centre, Kaula Lumpur, Malaysia. J Postgrad Med 2006;52(1):23-9.

[18] Farag HFM, Abdel-Fattah MM, Youssri AM. Epidemiological, clinical and prognostic profile of acute bacterial meningitis among children in Alexandria, Egypt. Indian J Med Microbiol 2005;23(2):95-101.

[19] Tiwari KB, Rijal B, Ghimire P. Acute Bacterial Meningitis in Nepal from January 2001 to March 2002. Nepal Med Coll J 2013:1-5.

[20] Surinder K, Bineeta K, Megha M. Latex particle agglutination test as an adjunct to the diagnosis of bacterial meningitis. Indian $\mathrm{J}$ of Med Microbiol 2007;25(4):395-7. 